\title{
Recurrent Melanoma
}

National Cancer Institute

\section{Source}

National Cancer Institute. Recurrent Melanoma. NCI Thesaurus. Code C7087.

The reemergence of a melanoma after a period of remission. 